ECCOMAS

Proceedia
COMPDYN 2021

$8^{\text {th }}$ ECCOMAS Thematic Conference on Computational Methods in Structural Dynamics and Earthquake Engineering M. Papadrakakis, M. Fragiadakis (eds.) Streamed from Athens, Greece, 28 - 30 June 2021

\title{
AMBIENT VIBRATION TEST ON AN EXISTING PRESTRESSED CONCRETE BRIDGE
}

\author{
A. De Angelis ${ }^{1}$, G. Esposito ${ }^{1}$, G. Maddaloni ${ }^{1}$, E. Cosenza $^{2}$ and M. Pecce ${ }^{1}$ \\ ${ }^{1}$ Department of Engineering, University of Sannio \\ Piazza Roma, 21, Benevento-Italy \\ e-mail: \{adeangelis, g.maddaloni, pecce\}@unisannio.it; giac9593@gmail.com \\ ${ }^{2}$ Department of Structures for Engineering and Architecture, University of Naples Federico II, \\ Via Claudio 21, Naples (80125), Italy \\ \{edoardo.cosenza\}@unina.it
}

\begin{abstract}
The dynamic test in situ of existing bridges is a very promising solution for assessing a reliable model, since it is more convenient than a load test requiring to organize the trucks and close the use of the infrastructure for a longer time. However its effectiveness depends on the test technique, the number, type and location of the sensors, but also on the numerical model that have to allow the introduction of the real boundary conditions. Cleary the dynamic identification of the structural behavior can be also the first step of a monitoring process to check the health of the construction during the time, therefore its effectiveness is fundamental.

In this paper the first results of the structural identification based on an ambient vibration test of an existing prestressed concrete bridge are presented. The selected case study is a bridge designed by Riccardo Morandi in 1952-1955 with the emerging technique of Prestressed Concrete (PC).

An important step of the process is the developing of the model though a survey and a wide investigation campaign, but also the role of the knowledge of the original design is highlighted due the complexity of the structure.
\end{abstract}

Keywords: Prestressed bridge, Dynamic test, Model updating, Finite element analysis, Operational Modal Analysis. 


\section{INTRODUCTION}

Structural identification for assessing and ensuring the safety and integrity of bridge structures is gaining much attention among researchers, due to the more frequent failure of bridges $[1,2]$, and also considering the existing heritage, in many countries near to the end of its service life.

Currently the dynamic tests are gaining increasing importance and efficiency especially to calibrate reliable numerical models [3-4] useful for a structural analysis, or to start a damage monitoring by two approaches. In one case the monitoring is carried out by the numerical model upgrading [5-7] in the other case a direct analysis of the signals [8-9].

It is noted that the first procedure is certainly more efficient and of great potential since a numerical model allows to investigate in detail the causes of a possible variation of the structural response [10-11], and then can be used to investigate the load-bearing capacity [12-13], its structural behavior under traffic [14] or seismic excitation and the efficiency of a prospective reinforcement interventions. However, the type and uncertainties of the model influence the process and the computational work is heavy.

In this paper the procedure of the structural identification is proposed underlining the various steps that contribute to individuate the real in-situ boundary conditions and the degradation of the construction through the variation of the elastic dynamic response [15-16]. The ambient vibration test (AVT) is carried out due to the simple applicability, albeit it is generally less effective than harmonically forced tests [17]. A brief review of testing methods for bridges explaining their advantages and limitations was presented by Salawu and Williams [18].

Moreover many researchers demonstrated that the environmental actions are able to excite the most significant modes of vibration in the low range of frequencies for flexible systems like cable-stayed bridges [19-20], large span arch bridges [21-22] and suspension bridges [23].

The bridge considered herein is particularly interesting because the static scheme and the technology adopted by Riccardo Morandi in his design was innovative and ambitious at the time but still currently the construction is complex and its analysis requires a detailed finite element model (FEM) that is useful to assess through tests in situ. Furthermore the real boundary conditions have to be assessed to better address the future design of strengthening interventions.

\section{OVERVIEW OF THE BRIDGE}

The case study bridge (Fig. 1), erected in Benevento and designed by Riccardo Morandi in early '50, although not so large, has a great importance since it connects two parts of the city crossing the creek San Nicola that goes through a valley with instable hillsides.

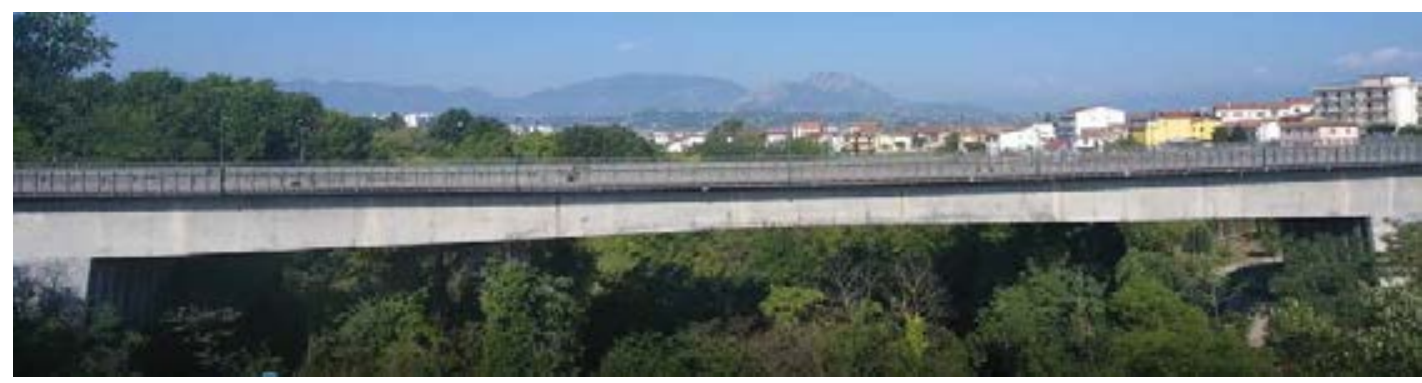

Figure 1: Current lateral view of San Nicola bridge. 
A detailed analysis of its conceptual design is reported in [24] evidencing a careful process of optimization by adopting an innovative method of construction with pre-casted segments.

The deck of San Nicola bridge is made of prestressed concrete cast in site with piers and foundations made of reinforced concrete. The static scheme is a portal frame composed by one main span $80.0 \mathrm{~m}$ long and two cantilevers of $20.0 \mathrm{~m}$ long as shown in Fig. 2.

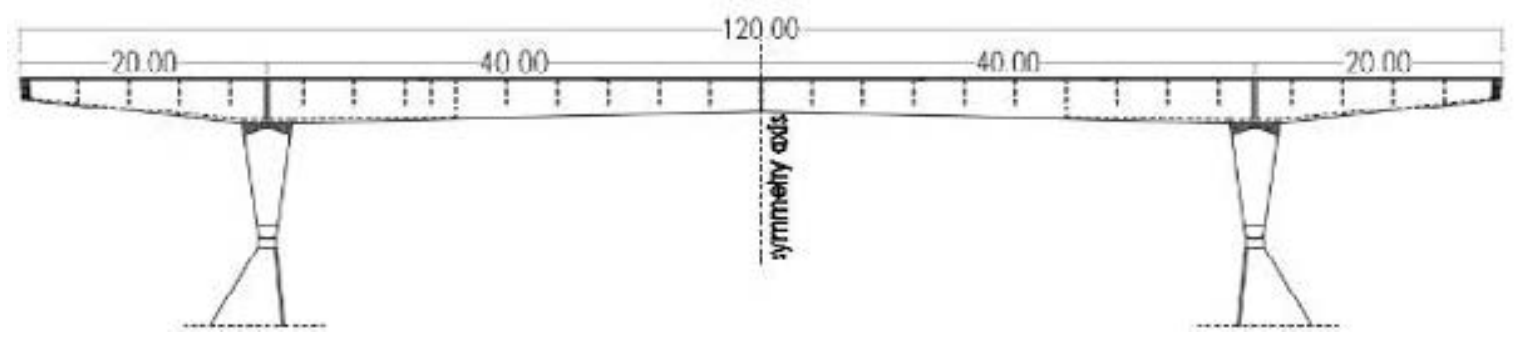

Fig. 2: Longitudinal scheme of the bridge.

The bridge deck is supported by two piers $9.40 \mathrm{~m}$ high; each pier, as shown in Fig. 3, was realized by eight columns of rectangular section, $40.0 \mathrm{~cm}$ thick and variable width from 1.50 $\mathrm{m}$ at the base to $4.00 \mathrm{~m}$ at the top, that are transversally connected at the base and top by a transverse beam.

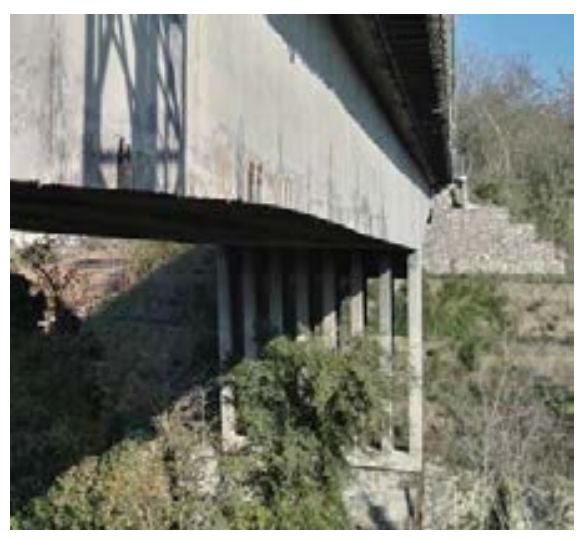

a)

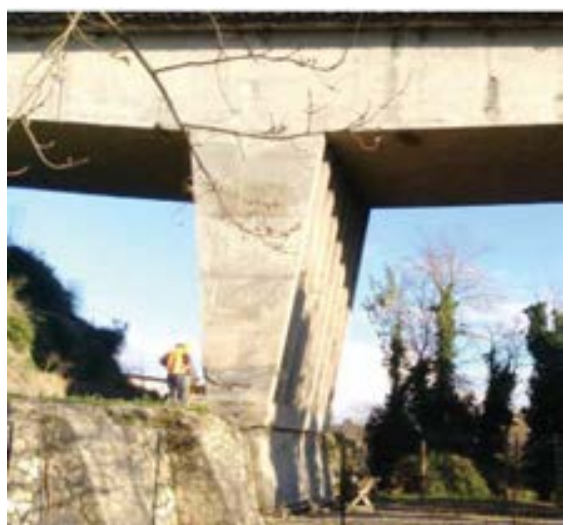

b)

Figure 3: Transversal and frontal view of the pier.

The piers are linked to the foundations underneath by hinges made of steel rebars to avoid bending moments on the foundation that have to also contain the thrust; in fact, the foundations also act as abutments.

The deck consists of a multicellular caisson whose webs vary in thickness, from a minimum of $13 \mathrm{~cm}$ at the midspan, to a maximum of $30 \mathrm{~cm}$ at the supports (see Fig. 4). Moreover, the deck shows varying-depth through the spans (beam with curved intrados), which characterizes an approximately linear shape giving also a beneficial arch effect. The depth of the deck cross section varies from a maximum of $3.60 \mathrm{~m}$ at the pier supports, to a minimum of $1.60 \mathrm{~m}$ at the ends of cantilevers and $2.70 \mathrm{~m}$ at the midspan.

The deck is characterized by internal tendons, symmetrical about midspan. The prestressing steel cables are composed of 27 aligned wires with diameter of $5 \mathrm{~mm}$ and are placed along a straight line in the top slab where the bending moment shows negative values and in the bottom slab in the midspan, but also curved cables are installed along the entire bridge. A portion of the original drawing with the prestressing cables is reported in Fig. 5. 

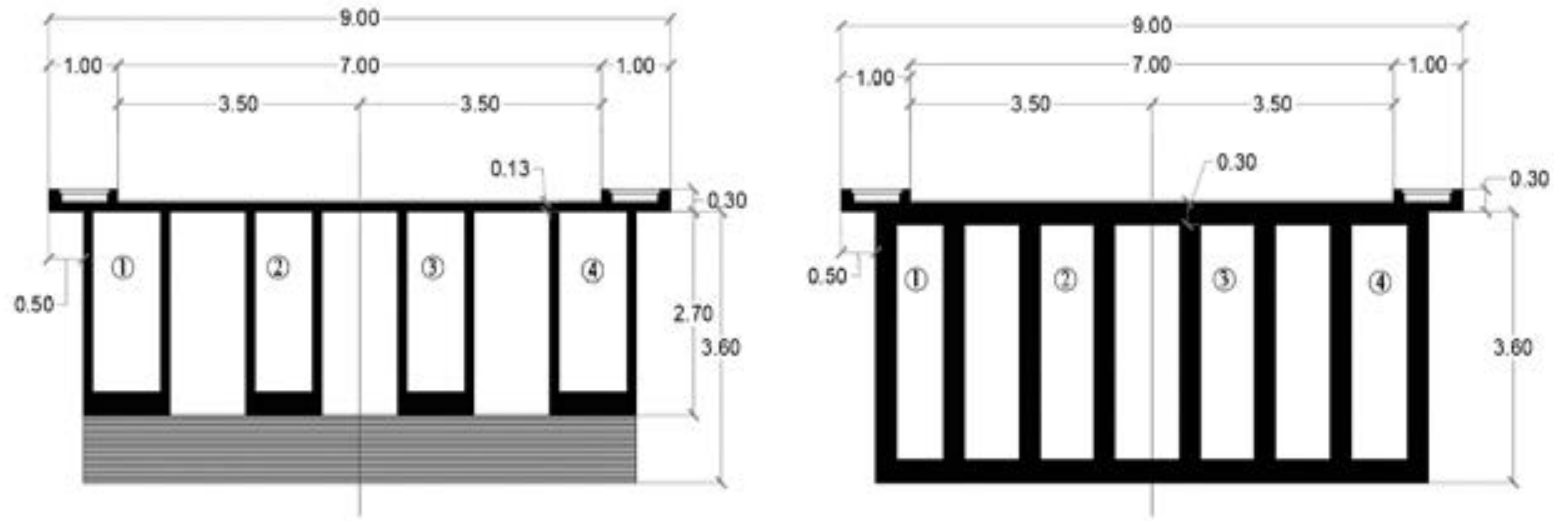

Figure 4: Cross sections of caissons at the midspan (left) and the supports (right).

The upper slab is $9.00 \mathrm{~m}$ width and consists of two traffic lanes, $7.00 \mathrm{~m}$ width, and two sidewalks $1.00 \mathrm{~m}$ width each one. Also the thickness is variable from $13 \mathrm{~cm}$ (in the area of the central span where there are no top cables) to $20 \mathrm{~cm}$.

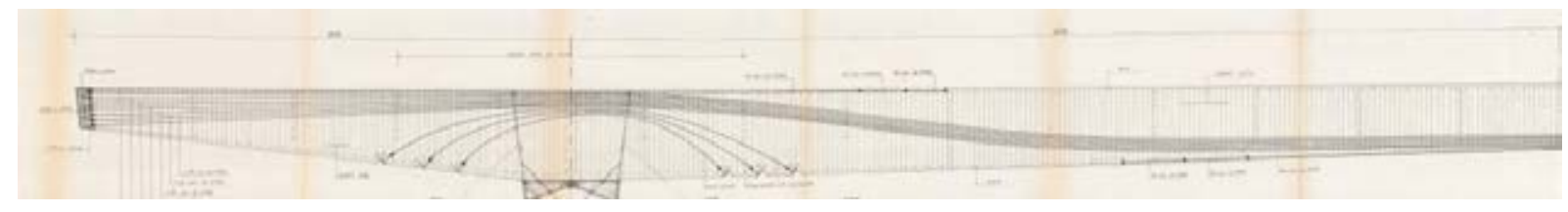

Figure 5: Original drawing with the prestressing cables

\section{SURVEY AND MATERIAL CARACHTERIZATION}

An extensive survey campaign, including surveys, essays and destructive tests on materials, i.e., concrete, steel reinforcement and prestressing steel cable, was carried out.

The geometric survey of the elements forming the deck and the piers shows that the structure was realized quite as designed.

Several essays were carried out on the deck highlighting the concrete cover degradation due to the disposal of the water, especially inside the multicellular caisson, however, no cracking is visible. The good conditions of the ducts and cables were detected except in specific parts where water stagnates. Pier and abutments concrete and reinforcements were also investigated pointing out a concrete surface degradation but limited corrosion of the steel rebars.

Regarding the materials, 14 cores were taken for the assessment of the compressive strength of the concrete. An average cubic compression strength $\left(\mathrm{R}_{\mathrm{cm}}\right)$ of $39.21 \mathrm{MPa}$ and $54.21 \mathrm{MPa}$ have been obtained for pier and deck, respectively. These average values were used to calculate the elastic modulus adopted in the model, described in section 4.

Also samples of prestressing steel cables were taken and tested in the laboratory but the elastic modulus of the steel is assumed from the literature.

\section{THE IN-SITU DYNAMIC TEST}

The AVT was chosen as dynamic test because it doesn't require any additive equipment and affects the use of the bridge for few time.

The dynamic behavior of the bridge has been analyzed by means of a preliminary numerical finite element model, described in the next section to establish the layout of the sensors shown in Fig. 6 that involved the choice of 30 measuring points. 
In order to identify both the bending, in plane and out-of-plane, and torsional modes, sensors were arranged in pairs at the long sides of the roadway with a distance of $6 \mathrm{~m}$ along the cantilever and 10-12 $\mathrm{m}$ along the center span.

The adopted instrumentation consists of five triaxial piezoelectric accelerometers with MEMS technology, characterized by an integrated 24-bit A/D converter of the Sigmadelta type. The sensors sample at a preset frequency of $1024 \mathrm{~Hz}$, transmitting the acquired signal directly to an acquisition unit, characterized by an industrial PC with a preinstalled Linux system.

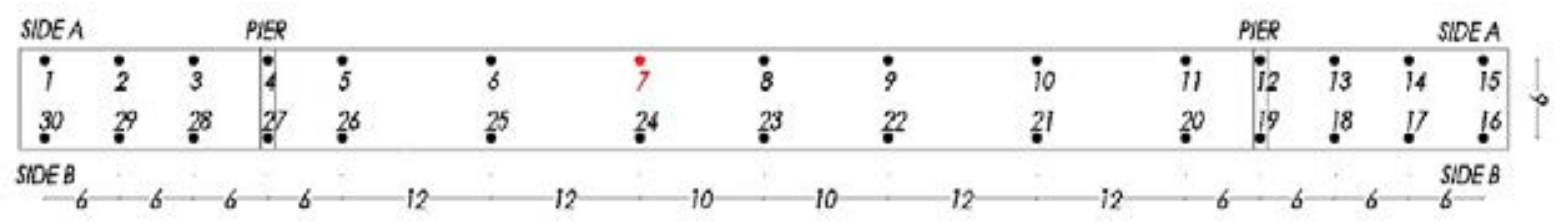

Figure 6: The layout of sensors in the dynamic test

Since only 5 accelerometers were available during the test, more test setups were performed, considering one sensor, indicated as n. 7 in Fig. 6, as reference transducer which was kept at the same location in all the setups. In each setup the accelerations were acquired in the presence of environmental actions (wind, passage of persons) [25] for a duration of 15 minutes at a frequency of $1024 \mathrm{~Hz}$.

The environmental records carried out at the points of measurement have been inspected and validated. Subsequently, each recording was filtered by the application of a Butterworthtype bandwidth filter of order 6 in the range $0.2-20 \mathrm{~Hz}$. Subsequently, the time series were decimated to obtain a final sampling frequency of $20 \mathrm{~Hz}$. It is worth to note that filtering performed before decimation ensures the absence of aliasing problems in the frequency range of interest.

The data processing and the extraction of modal shapes were carried out with the commercial program ARTeMIS [26] both in the frequency and time domain to obtain the natural frequencies, damping ratios and modal shapes of different modes of vibration of the structure. In particular the Enhanced Frequency Domain Decomposition (EFDD) [27] and the data driven Stocastic Subspace Identification (SSI) [28] were used as output-only techniques.

The analysis of the data and the comparison of the results provided by the various methods allowed the identification of the fundamental modes of the structure and the validation of the data obtained. Specifically, the comparison of the estimates provided by the different methods (EFDD, SSI) showed a maximum frequency deviation of $0.6 \%$ and CROSS-MAC values not less than 0.87 for all identified modal shapes.

Fig. 7 shows the modal shapes and values of natural frequencies and damping ratios for each of the identified modes. The latter can be classified as follows:

1. Transversal bending mode;

2. Vertical bending mode;

3. Vertical torsional mode.

In addition, the identified modes are all normal modes, as can be seen from the examination of the complexity plots shown in Fig. 8. It is hardly necessary to point out that the imaginary components present in some modes are minimal, clearly attributable to the effects of the measuring noise. 

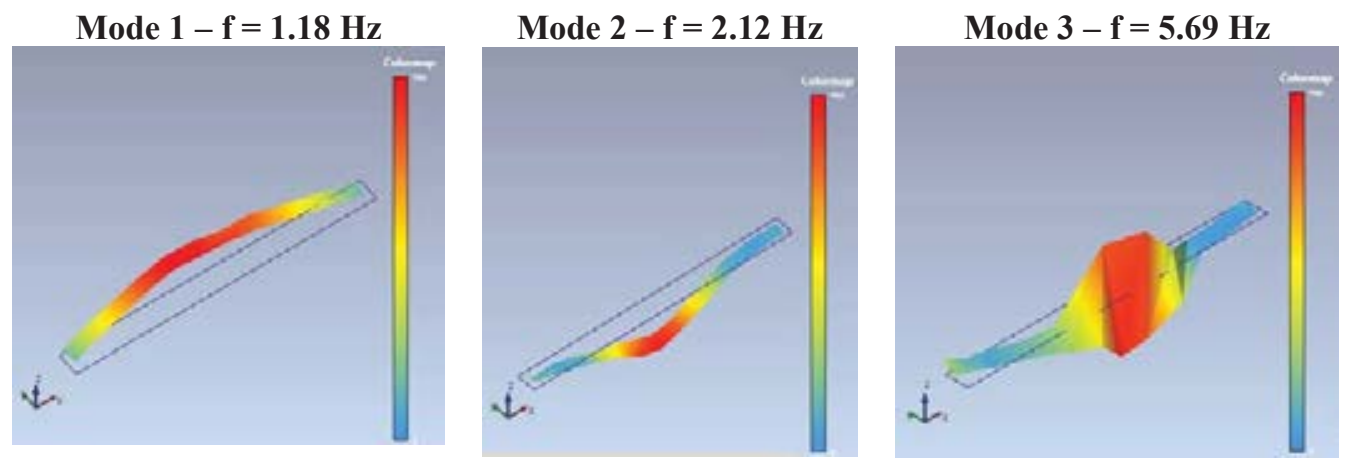

Figure 7: Experimental mode shapes.

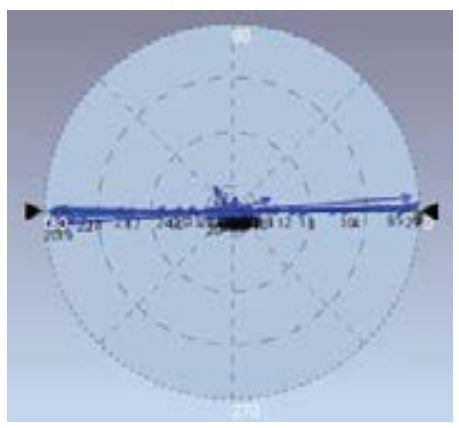

Mode 1

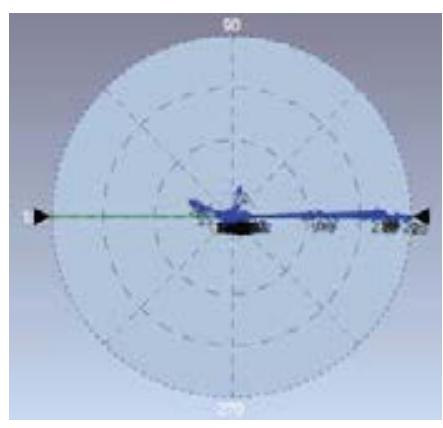

Mode 2

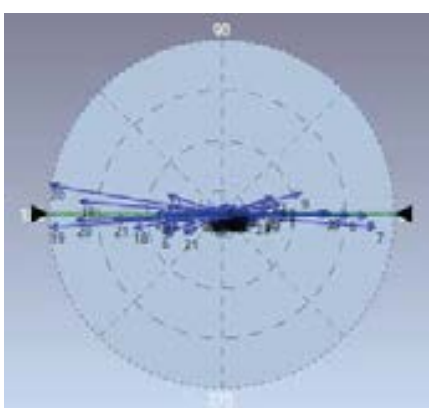

Mode 3

Figure 8: Complexity plots of the experimental mode shapes.

\section{THE NUMERICAL MODEL OF BRIDGE}

The FE model of the bridge assumed as case study was developed by the software SAP2000 [29]. The various components of the structure were modeled considering their real geometry with mono-dimensional (frame) and bi-dimensional (shell) finite elements, getting a three-dimensional model including deck and piers restrained at the base by hinges.

The concrete section was considered entirely reactive assuming prestressing effect efficient. The deck was modeled by thin "shell" elements, with 4 nodes and a formulation that combines membrane and plate-bending behavior Stress and strain are evaluated in the local coordinate system of the elements in $2 \times 2$ Gaussian integration points and are extrapolated in the connection nodes between the elements. The nodes of discretization of the deck are approximately 4600 with a mesh of $1 \times 0.7 \mathrm{~m}$ for the upper slab.

The piers were modeled using frame elements for the 8 pillars and shell elements for the transverse elements at the top and the button. Moreover, tendon elements were added in the model to simulate the presence of prestressed cables. Tendon elements are an object type that can be inserted into other objects (Frame, Shell, Plane, Asolid, and Solid) to simulate the effects of pre-stressing but in this dynamic analysis their effect is the stiffness and mass contribution.

Errore. L'origine riferimento non è stata trovata.9 shows the view of the model implemented by the software SAP2000 [29].

The elastic modulus of concrete was evaluated by the Eurocode 2 formulation [30] using the mean concrete strength measured by the in situ tests, and resulted of $34700 \mathrm{MPa}$ and 32700 for the concrete of piers and deck respectively. Furthermore a value of $196500 \mathrm{MPa}$ from literature was adopted for the steel cables. 


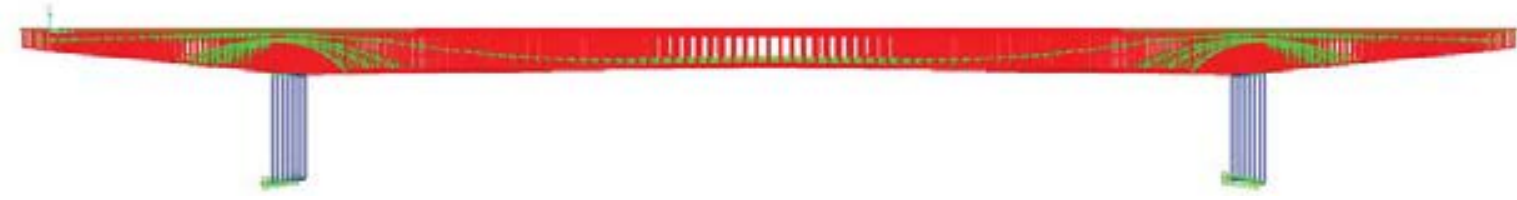

a)

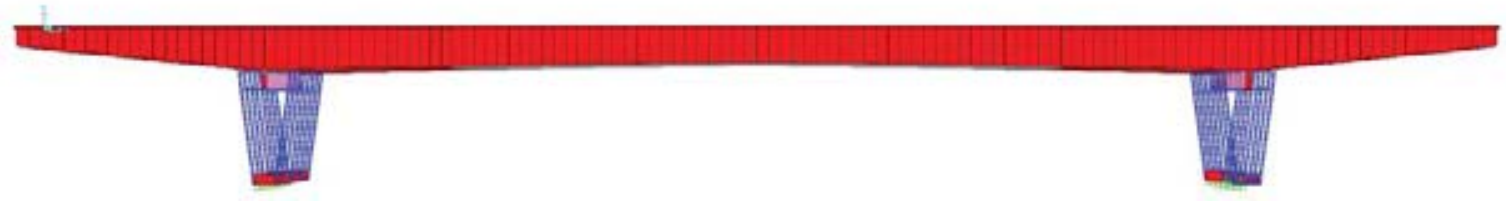

b)

Figure 9: a) FEM model of the bridge including prestressed cables; b) extruded view of the model.

Fig 10 shows the deformed shapes of the first nine numerical modes that involve always the deck structure of the bridge and the piers for the modes that have horizontal components.

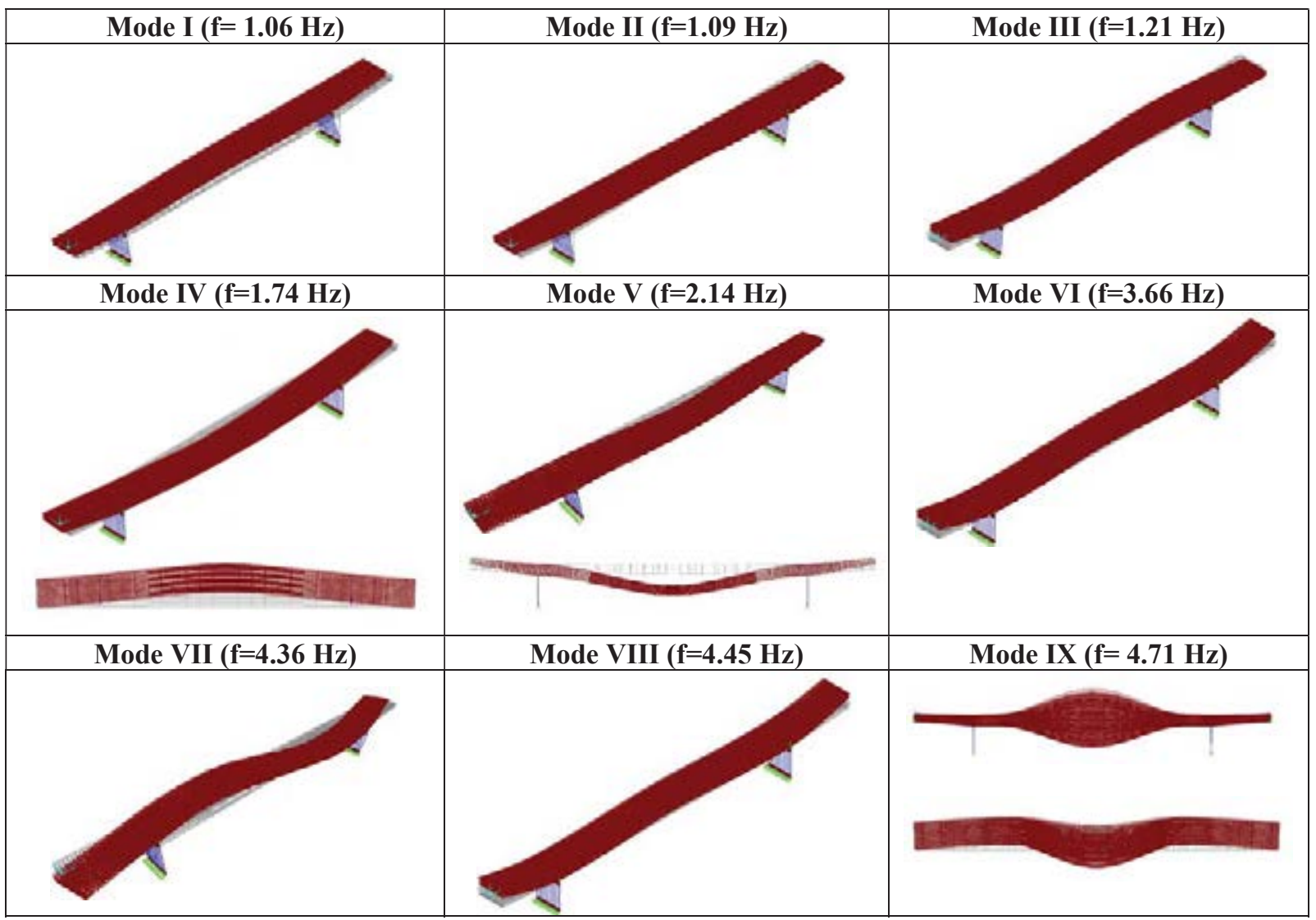

Figure 10: Numerical mode shapes of the bridge.

\section{FIRST RESULTS OF THE STRUCTURAL IDENTIFICATION}

Once the model was specialized on the basis of the in site detected geometry and the collected values of material mass and stiffness, a first comparison between the numerical and experimental results was carried out in terms of frequencies and mode shapes. The consistency of 
the latter comparison was measured with the MAC index - Modal Assurance Criterion which provides a measure of the degree of linearity between the vectors of the mode shapes [31]. A MAC index value close to unity indicate a high level of correspondence between the compared mode shapes. The results are reported in Table 1. The numerical model provides, among the first nine mode shapes, the experimental mode shapes identified with the dynamic test. In particular, the experimental modes correspond respectively to the fourth, fifth and ninth numerical ones as can be observed in Fig. 10.

Table 1. Theoretical-experimental comparison

\begin{tabular}{ccccc}
\hline & Experimental & \multicolumn{3}{c}{ Numerical } \\
\hline Mode N. & $\mathbf{f e x p}_{\exp }[\mathrm{Hz}]$ & Mode N. & $\mathbf{f}_{\text {FEM }}[\mathbf{H z}]$ & MAC \\
\hline 1 & 1.18 & 1 & 1.19 & 0.86 \\
\hline 2 & 2.12 & 5 & 2.12 & 0.98 \\
\hline 3 & 5.69 & 9 & 4.72 & 0.76 \\
\hline
\end{tabular}

As can be noted from Table 1 the assessment between numerical and experimental returns, with reference to the fundamental modes of the structure, a good agreement in terms of frequency and MAC for the two first experimental modes. Otherwise mode 3 shows a slightly lower correlation between the experimental mode shape and the corresponding numerical data, with a low MAC index of 0.76 .

It is worth to note that the numerical model provides many in-plane and out of-plane bending modes of the deck that have not been detected by the dynamic test. Thus, the model needs to be calibrated to identify the actual conditions of the bridge, especially in terms of constraints, that avoid or reduce the movement of the bridge in the deck plane. Therefore, in the paper a first manually updating of the model was performed changing the following prominent items in agreement with physical phenomena due to real conditions observed during the investigation:

1) A fixed support was assigned to the base of the piers in the transverse direction (short dimension of the deck) because the hinge at the base of the pier may not be activated in the transverse direction for the environmental vibrations due to friction between the concrete of the pier and the foundation.

2) Fixed supports in transversal and longitudinal direction were inserted at the edges of the cantilevered spans to take in account that the longitudinal and transverse displacements are prevented because the gap between the bridge and the road has been filled with cement.

3)elastic supports were adopted at the longitudinal edges in vertical direction to take into account that gap below the bridge is not enough to avoid the support effect of the gabions and reinforced soil. A first calibration of the restraints stiffness has been made but this aspect needs of further study.

4) A rectangular beam was arranged along the two longitudinal sides of the bridge to consider the stiffness effect along the transverse direction due to the sidewalk added in 1982 by a steel structure bolted to the bridge. equivalent to.

5) The elastic modulus of the concrete for the piers (24000 MPa) was reduced to take account of the degradation phenomena of concrete cover evidenced during the in-situ survey.

The above considerations, properly introduced in the numerical model modified the mode shapes of the model, and led to the correspondence of the order between experimental and numerical modes. In Table 2 the comparison of numerical and experimental modes after the updating is shown. An improvement of the correspondence between numeric and experimental behavior is also confirmed by the increment of MAC, after the first manual updating 
of the model, that was necessary to introduce the correct boundary conditions that correspond to real circumstances and not to numerical optimization. Clearly a further step is necessary in the updating process in order to reduce the difference in frequency between experimental and numerical modes by a better assessment of the parameters values as the elastic modulus of the materials, the restraints conditions and the elasticity of the constraints.

Table 2. Theoretical-experimental comparison after updating

\begin{tabular}{ccccc}
\hline \multicolumn{3}{c}{ Experimental } & \multicolumn{3}{c}{ Numerical } \\
\hline Mode N. & $\mathbf{f}_{\exp }[\mathrm{Hz}]$ & Mode $\mathbf{N}$ & $\mathbf{f}_{\text {FEM }}[\mathrm{Hz}]$ & MAC \\
\hline 1 & 1.18 & 1 & 1.91 & 0.97 \\
\hline 2 & 2.12 & 2 & 2.16 & 0.97 \\
\hline 3 & 5.69 & 3 & 4.16 & 0.80 \\
\hline
\end{tabular}

\section{CONCLUSIONS}

The study presents the complete procedure of structural identification of an existing bridge and the first results of the consequent model updating. The selected case study, that is a complex, even if not large, structure designed by Riccardo Morandi in '50 years, evidenced the following general aspects:

- The AVT is a suitable procedure to the define the experimental behavior of a structure in the linear field because it doesn't require the time and organization for application of actions; however a reliable numerical elaboration of the results is necessary with more than a technique. A few number of sensors can be used applying more than one setup and combining the results by a suitable technique. In the case study 5 sensors were available but 8 setup allowed to have experimental results of 30 points along the bridge.

- The numerical model has to be developed considering the aspects that is necessary to update by the identification process. The basic model has to be developed considering the results of a detailed in situ investigation on geometry, materials and boundary conditions of the structure.

- A first updating process addressed by physical considerations of the conditions that can bring the numerical model near to the experimental behavior is important to avoid that a numerical optimization process can use other properties to attain the final results. In the case proposed herein some constraints are due to real in situ conditions (filling of the gaps between the road and the bridge not considered in the design) that influence the linear elastic response, therefore their presence have to be introduced before starting an update process of the elastic properties of the construction.

The strategy of carrying out a dynamic experimental test to calibrate a reliable model provides a good structural identification, allowing to accurately identify the real boundary conditions of the structure, not always possible without in situ tests. The presented work is in progress to complete the model updating and compare the behavior of the structure evidenced by the dynamic test with the one obtained by a load in situ test.

\section{REFERENCES}

[1] J. Scheer, Failed Bridges, Case Studies, Causes and Consequences. Ernst \& Sohn, 2010. 
[2] Calvi, G. M., Moratti, M., O’Reilly, G. J., Scattarreggia, N., Monteiro, R., Malomo, D., Calvi, P. M., Pinho, R., (2019). Once upon a time in Italy: The tale of the Morandi Bridge. Struct. Eng. Int. 29 (2): 198-217.

[3] Altunisik, A.C., Bayraktar, A., (2017). Manual model updating of highway bridges under operational condition. Journal of Structures and Systems, 19: 39-46.

[4] A. Morassi, S. Tonon, Dynamic testing for structural identification of a bridge, J. Bridge Eng. ASCE 13 (6) (2008) 573-585.

[5] Van der Auweraer H, Peeters B. International research projects on structural health monitoring: an overview. Struct Health Monit 2003;2:341-58.

[6] Ko JM, Ni YQ. Technology developments in structural health monitoring of large-scale bridges. Eng Struct 2005; 27:1715-25.

[7] Hsieh KH, Halling MW, Barr PJ. Overview of vibrational structural health monitoring with representative case studies. J Bridge Eng 2006;11(6):707-15.

[8] Caetano E, Cunha A, Magalhães F. Studies for controlling human-induced vibration of the Pedro e Ins footbridge, Portugal. Part 2: implementation of tuned mass dampers. Eng Struct 2010;32:1082-91.

[9] Chen WH, Lu ZR, Lin W, Chen SH, Ni YQ, Xia Y, Liao WY. Theoretical and experimental modal analysis of the Guangzhou new tv tower. Eng Struct 2011;33:3628-46.

[10] Dilena M, Morassi A, Perin M. Dynamic identification of a reinforced concrete damaged bridge. Mech Syst Signal Pr 2011;25:2990-3009.

[11] Alvandi A, Cremona C. Assessment of vibration-based damage identification techniques. J Sound Vib 2006;292:179-202.

[12] Askegaard, V. and Lanso, H.E. Correlation between Changes in Dynamic Properties and Remaining Carrying Capacity, Materiaux et Constructions, Vol. 19, No. 109, 11-20 (1986).

[13] Marefat, M.S., Ghahremani-Gargary, E. and Ataei, S. (2004), "Load test of a plain concrete arch railway bridge of 20-m span”, Constr. Build. Mater., 18, 661-667.

[14] Frýba, L. and Pirner, M. (2001), "Load tests and modal analysis of bridges", Eng. Struct., 23, 102-109.

[15] Mottershead JE, Friswell MI. Model updating in structural dynamics: a survey. J Sound Vib 1993;167:347-75.

[16] Zàrate BA, Caicedo JM. Finite element model updating: multiple alternatives. Eng Struct 2008;30:3724-30.

[17] Salawu O. S., and Williams C., Bridge assessment using forced vibration testing, J. Struct. Eng., 121(2), 161-173, 1995.

[18] Salawu, O.S. and Wiliams, C. Review of full-scale dynamic testing of bridge structures, Engineering Structures, 17, 2,113-12, Elsevier Science, (1995).

[19] Wilson JC, Liu T. Ambient vibration measurements on a cable-stayed bridge. Earthquake Eng Struct Dyn 1991;20:723-47.

[20] Gentile C, Martinez y Cabrera F. Dynamic investigation of a repaired cable stayed bridge. Earthquake Eng Struct Dyn 1997;26(1):41-59. 
[21] Calcada R, Cunha A, Delgado R. Dynamic analysis of metallic arch railway bridge. J Bridge Eng, ASCE 2000;7(4):214-22.

[22] Magalhães F, Cunha A, Caetano E. Dynamic monitoring of a long span arch bridge. Eng Struct 2008;30(10):3034-44.

[23] Brownjohn JMW, Dumanoglu AA, Severn RT. Ambient vibration survey of the Faith Sultan Mehmet (second Bosporus) suspension bridge. Earthquake Eng Struct Dyn 1992;21:907-24.

[24] M.R. Pecce, F. Santamato, E. Ciampa, E. Cosenza, The design approach of a Prestressed Concrete bridge constructed in 1950s in Italy. Proc. of the International fib Symposium on Conceptual Design of Structures, Instituto de Ciencias de la Construcción Eduardo Torroja, Madrid, Spain, Sept 26-28, 2019.

[25] Rainieri C. \& Fabbrocino G., Learning operational modal analysis in four steps. $6^{\text {th }}$ IOMAC International Conference on Operational Modal Analysis, Gjion, 2015.

[26] SVS 2010. ARTeMIS extractor 2010 release 5.0. http://www.svibs.com/.

[27] Brincker R, Ventura CE, Andersen P. Damping estimation by Frequency Domai Decomposition. In: Proc. 19th int. modal analysis conf. IMAC-XIX. 2001.

[28] van Overschee P, De Moor B. Subspace identification for linear systems: theory, implmentation, applications. Boston (London, Dordrecht): Kluwer; 1996.

[29] Computers and Structures. SAP2000 Version 18; Computers and Structures: Walnut Creek, CA, USA, 2016.

[30] EN 1992-1-1, Design of concrete structures - General rules and rules for buildings, European Committee for Standardization, CEN, Brussels (2004).

[31] Allemang R. J., The Modal Assurance Criterion -Twenty Years of Use and Abuse, Sound And Vibration, 2003. 